\title{
FRACTURE MECHANICS ANALYSIS OF FATIGUE STRENGTH OF TRANSVERSE FILLET WELDED JOINT OF HIGH STRENGTH STEEL
}

\author{
By Koei TAKENA*, Fumio ITOH**, Fumio NISHINO*** and Chitoshi MIKI****
}

\begin{abstract}
It is said that fatigue strength decreases according as thickness increases. In the Honshu-Shikoku Bridges, a material which is by far thicker than the one for former bridges is used. The effect of thickness of main plate and diaphragm was analyzed by the fracture mechanics method. The results of this reseach were used for fatigue design of the Honshu-Shikoku Bridges.

Keywords: fatigue, transverse fillet welded joint, high strength steel
\end{abstract}

\section{INTRODUCTION}

It has been shown that the fatigue strength of welded joint would be expected to decrease with increasing of plate thickness. That is the so-called size-effect. There are many factors which relate to the occurrence of size-effect. These include stress distribution, welding residual stress, configuration and size of weld defect and material. Gurney ${ }^{1)}$ indicated that the fatigue strength of welded joint is inversely proportional to the power of one quater of the plate thickness from the review of available experimental data. This plate thickness effect has already been introduced in some designs ${ }^{2}$.

In Honshu-Shikoku Bridges, fatigue design values for diaphragm joints in box section truss chords are based on the fatigue test results of box-section and $\mathrm{H}$-section specimens which were reported in previous paper $^{33}$. However, as the plate thicknesses of these specimens are $15 \mathrm{~mm}$ and $20 \mathrm{~mm}$, they are very much thinner than these of actual bridge members which are up to $75 \mathrm{~mm}$. As a supplement to the previous paper ${ }^{3)}$ , the plate thickness effect on the fatigue strength of diaphragm joint is parametrically studied by using fracture mechanics concept in this paper.

\section{ANALYTICAL METHOD}

Fracture mechanics analysis of transverse fillet welded joints in this study is based on the results of HC-type specimens reported in the previous paper $^{3)}$. This HC-type specimens simulated diaphragm detail of box section truss chord which included transverse fillet welding which started from the inside of scallop

* Member of JSCE, Dr. Eng., Shin Nippon Giken, (Minatoku, Tokyo)

** Member of JSCE, Japan Construction Method and Machinary Reseach Institute, (Fuji, Shizuoka)

*** Member of JSCE, Ph. D., Professor, Department of Civil Engineering, University of Tokyo, (Bunkyo-ku, Tokyo)

**** Member of JSCE, Dr. Eng., Associate Professor, Department of Civil Engineering, Tokyo Institute of Technology, (Meguro-ku, Tokyo) 
and longitudinal welding between flange and web. Most fatigue cracks initiated from the toes of fillet welds of diaphragm at scallops where welding position changed to the horizontal from the vertical. Fig. 1 shows the measured values of flank angle and toe radius along the weld toe of $\mathrm{HC}-1$ specimen. At the corner of scallops, toe profiles changed ; flank angle became steep and toe radius became small. The values of flank angle and toe radius at weld toe for the analysis were $120^{\circ}$ and $0.2 \mathrm{~mm}$, respectively based on these measured results.

The initial crack was assumed to be half circle whose radius was $a_{i}$. As the crack grows as the shape of half-ellipse, the behavior of fatigue crack growth can be predicted by calculating the stress intensity factor ranges at point $\mathrm{A}$ and $\mathrm{B}$ (Fig. 2), $\Delta K_{a}$ and $\Delta K_{b}$, respectively. The values of $\Delta K_{a}$ and $\Delta K_{b}$ were calculated as follows ${ }^{6}$.

$\Delta K_{A}=F_{e A} \cdot F_{s A} \cdot F_{t A} \cdot F_{g_{A}} \cdot S_{r} \sqrt{\pi a}, \Delta K_{B}=F_{e B} \cdot F_{S B} \cdot F_{t B} \cdot F_{g_{B}} \cdot S_{r} \sqrt{\pi a}$

where, $S_{r}$ is stress range, $F_{t A}$ and $F_{t B}$ are the correction factors for the thickness $(T)$ and the width $(W)$, respectively. $F_{g}$ is the correction factor for stress gradient. In order to obtain the value $F_{g}$, the stress distributions in the direction of plate thickness were calculated by using the finite element method. Here, the plane strain elements were used and the minimum element size was $0.03 \mathrm{~mm} . F_{e}$ is the correction factor for the crack configuration, and $F_{s}$ is the correction factor for the surface crack. These factors used here are expressed as follows:

$$
\begin{aligned}
& F_{e A}=1 / E(k), F_{e B}=F_{e A} \cdot \sqrt{a / b}, E(k)=\int \sqrt{1-\left(1-(a / b)^{2}\right) \cdot \sin ^{2} \xi} d \xi, \\
& F_{S A}=1.12-0.12 \cdot(a / b), \quad F_{s B}=1 \\
& F_{t A}=\sqrt{\sec (\pi a / 2 T)}, \quad F_{t B}=\sqrt{\sec (\pi b / 2 W)}, \quad F_{g_{B}}=K_{t}\left(K_{t}\right. \text { is stress concentration factor) }
\end{aligned}
$$

The following relationship ${ }^{5)}$ which was obtained experimentally for welded joints with high tensile residual stress was employed for the prediction of fatigue life.

$d a / d N=5.47 \times 10^{-9}\left(\Delta K^{3}-2.5^{3}\right),(d a / d N$ is crack growth rate $: \mathrm{mm} /$ cycle $),(\Delta K: \mathrm{MPa} \sqrt{\mathrm{m}})$

The final crack depth was set equal to $90 \%$ of plate thickness, which is not a sensitive factor because the fatigue crack growth rate increases acceleratively with the extention of fatigue crack.

In order to set the suitable size of initial crack for the following parametric analysis, the fatigue crack propagation life curves of HC-type specimens were predicted with changing the value of initial crack size. Fig. 3 shows the predicated results with fatigue test results. The test results are very close to the predicted fatigue curve of $a_{i}=0.05 \mathrm{~mm}$ in radius. Therefore, this value was used for the parametric analysis.

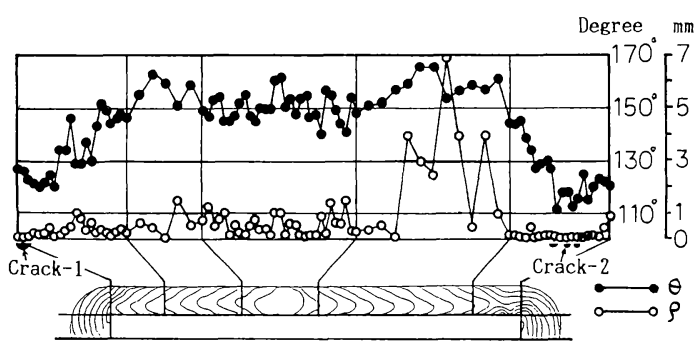

Fig. 1 Flank Angle and Redius at Weld Toe of $\mathrm{HC}-1$ Specimen.

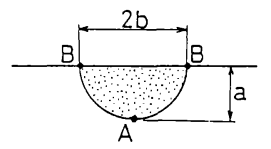

Fig. 2 Crack Shape.

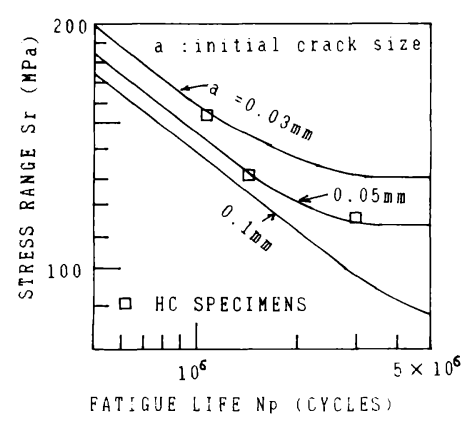

Fig. 3 Predicted $S_{r}-N_{\rho}$ Relations and Test Results. 


\section{RESULTS OF PARAMETRIC ANALYSIS}

The plate thickness effect may vary with the thickness of main plate $(T)$, diaphragm $(t)$ and size of fillet weld $(s)$. There are the following trends in actual bridge member of Honshu-Shikoku Bridges.

(1) In the case where high strength steels are used as materials of main plates, thicknesses of most main plates $(T)$ are greater than $35 \mathrm{~mm}$.

(2) The thickness of diaphragm ( $t$ ) is not proportional to $T$, being about $12 \mathrm{~mm}$ in the range where $T$ is more than $35 \mathrm{~mm}$.

(3) The sum total of throat sizes of fillet welds is nealy equal to the thickness of diaphragm. For example, in case of $t=12 \mathrm{~mm}, s$ is $9 \mathrm{~mm}$. Hereafter, the size of joint of $T=36 \mathrm{~mm}, t=12 \mathrm{~mm}$ and $s=$ $9 \mathrm{~mm}$ is called standard as shown in Fig. 4.

Fatigue strengths at one million cycles were calculated changing $T, t$ and $s$ as follows on the condition of $\rho=120^{\circ}$ and $s / t=9 / 12$. Thickness ratios $(t / T)$ are $1,1 / 2,1 / 3,1 / 5$ and $1 / 6$ for $T=36 \mathrm{~mm}, 48 \mathrm{~mm}$, $60 \mathrm{~mm}$, and $72 \mathrm{~mm}$, respectively.

The calculated results are shown in Fig. 5. In the case where $t / T$ is constant, the fatigue strength decreases according as $T$ increases. Fatigue strengths of joints with constant thickness of diaphragm of $t$ $=12 \mathrm{~mm}$ are expressed by a dotted line in Fig. 5 . In this case, fatigue strengths do not decrease with increasing of the plate thickness of main plate. It is stipulated in the specifications of the Honshu-Shikoku Bridges $^{4)}$ that this joint should be classified as category $\mathrm{C}$ regardless of thickness of main plate.

Twe causes are considered in plate thickness effect. One is that stress concentration factor increases according as $T$ increases as $\rho$ is constant. The other is that, when $\rho$ is proportional to $T$ (that is, stress concentration factor is constant), the region of high stress becomes wide with increasing of $T$. Fig. 6 shows analytical results about the three cases of $t / T=1 / 3$, that is, case of $\rho=0.2 \mathrm{~mm}$ with $T=36 \mathrm{~mm}$ and those of $\rho=0.2 \mathrm{~mm}$ and $0.4 \mathrm{~mm}$ with $T=72 \mathrm{~mm}$. Stress concentration factor of $\rho=0.2 \mathrm{~mm}$ with $T=$ $36 \mathrm{~mm}$ is equal to that of $0.4 \mathrm{~mm}$ with $T=72 \mathrm{~mm}$. Rate of the decrease of fatigue strength by the latter cause was $6 \%$ and one by the former was $7 \%$. In this example, both are nearly equal.

Fig. 7 shows relations between relative fatigue strengths at one millon cycles and relative main plate thickness $(T / 36)$. Fig. 8 shows relations between relative fatigue strength at one millon cycles and thickness ratio $(t / T)$ of rib plate and main plate. These lines are able to be expressed as follows by $S_{b}$ which is fatigue strength of standard size joint.

$$
\begin{aligned}
& t / T \leqq 0.45 S=S_{b} \cdot(36 / T)^{0.2} \cdot(T / 3 t)^{0.3} \\
& t / T>0.45 S=0.9 \cdot S_{b} \cdot(36 / T)^{0.2} \cdot(T / 2.5 t)^{0.1}
\end{aligned}
$$

\section{CONCLUDING REMARKS}

The principal finding from this study on transverse fillet welded joint are as follows.

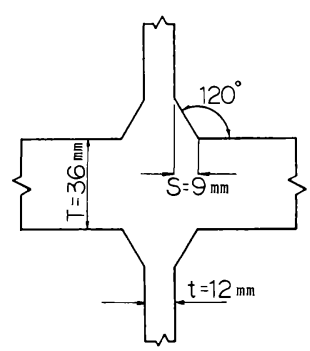

Fig. 4 Standard Size of Welded Joint.

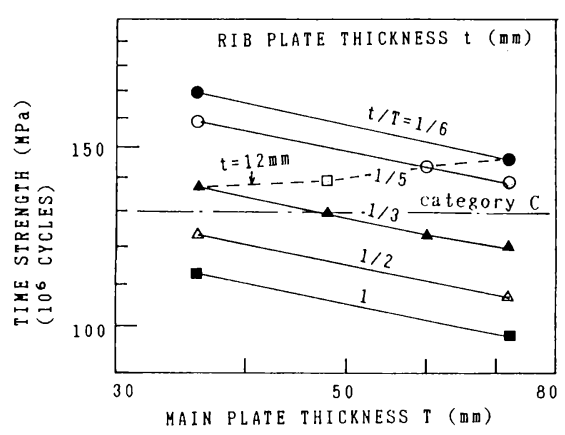

Fig. 5 Effects of Main Plate Thickness and Rib Plate One on the Fatigue Strength.

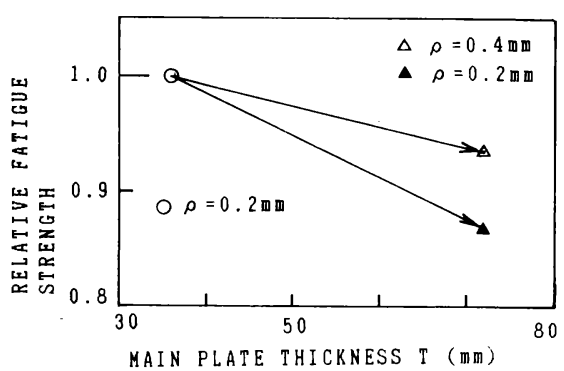

Fig. 6 Influence of Toe Radius on Effects of Thickness. 


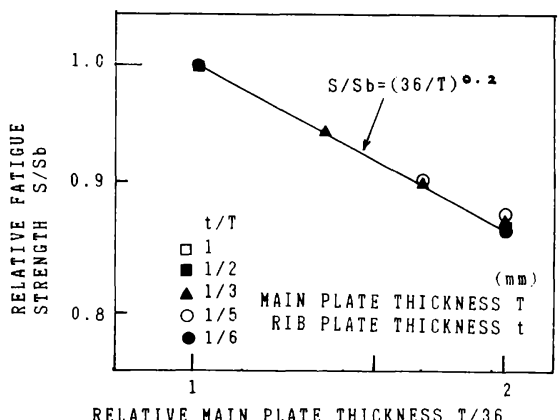

Fig. 7 Effects of Main Plate Thickness on the Fatigue Strength.

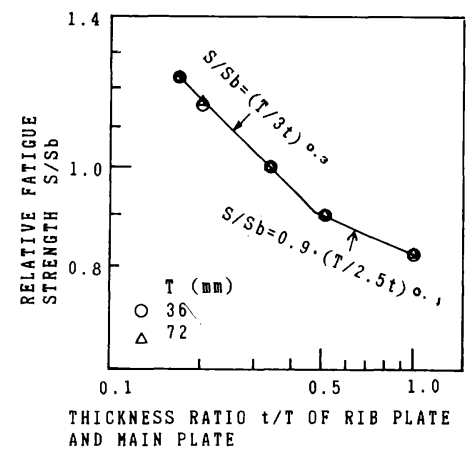

Fig. 8 Effects of Thickness Ratio of Main Plate and Rib One on the Fatigue Strength.

(1) An predicated fatigue life curve of initial crack size $0.05 \mathrm{~mm}$ is very close to the test results.

(2) The fatigue strength decreases, according as thickness of main plate or diaphragm increases. This thickness-effect is able to be expressed as follows.

$t / T \leqq 0.45 S=S_{b} \cdot(36 / T)^{0.2} \cdot(T / 3 t)^{0.3}$

$t / T>0.45 S=0.9 \cdot S_{b} \cdot(36 / T)^{0.2} \cdot(T / 2.5 t)^{0.1}$

where, $T$ is thickness of main plate. $t$ is that of diaphragm. $S_{b}$ is a fatigue strength of joint of $T=36 \mathrm{~mm}$.

(3) In the case that thickness of diaphragm is constant, the fatigue strength does not decrease if thickness of main plate increases. It was stipulated in the specifications of the Honshu-Shikoku Bridges that this joint shoud be classified as category $C$ regardless of thickness of main plate.

\section{REFERENCES}

1) Gurney, T. R. : The Influence of Thickness on the Fatigue Strength of Welded Joints, Second International Conference on Behavior of Offshore Structures, London, 1979.

2) United Kingdom, Department of Energy, Offshore Installations : Guidance on Design and Construtions Proposed New Fatigue Design Rules for Steel Welded Joints in Offshore Structure, 1982.

3) Takena, K., Shimokawa, H., Itoh, F. and Miki, C. : Fatigue Strength of Diaphragm Joint in Box-Section Truss Chord of High Strength Steel, Proc. of JSCE, No. 374/ I -6, 1986.

4) JSCE : Report on the Steel Superstructure of the Honshu-Shikoku Bridges, 1983 (in Japanese).

5) Miki, C., Nishino, F., Hirabayshi, Y. and Takena, K. : Influence of Residual Welding Stress on Fatigue Crack Growth Rate, Proc. of JSCE, No. 356/ I-3, 1984.

6) Albrecht, P. and Yamada, K. : Rapid Calculation of Stress Intensity Factor, Proc. of ASCE, Vol. 103, No. St 2, 1977.

(Received February 8 1988) 